\title{
Evaluation of Improvement in Quality of Life and Physical Activity After Total Knee Arthroplasty in Greek Elderly Women
}

\author{
Th. Tsonga ${ }^{1}$, S. Kapetanakis ${ }^{*}, 2$, C. Papadopoulos ${ }^{2}$, J. Papathanasiou $^{4}$, N. Mourgias ${ }^{1}$, N. Georgiou ${ }^{1}$, \\ A. Fiska ${ }^{2}$ and K. Kazakos ${ }^{3}$ \\ ${ }^{I}$ Department of Physiotherapy and Rehabilitation, General Hospital Amalia Fleming, Athens, Greece \\ ${ }^{2}$ Department of Anatomy, Medical School of Alexandroupolis, Greece \\ ${ }^{3}$ Department of Orthopaedic Surgery, University Hospital of Alexandroupolis, Greece \\ ${ }^{4}$ Department of Physical Rehabilitation, Medical School of Plovdiv, Bulgaria
}

\begin{abstract}
Background: The aim of this study was to evaluate the changes in quality of life of patients after total knee arthroplasty and to assess the changes in physical activity by using a self-reported questionnaire and by counting the number of steps 3-6 months after post-operatively.

Methods: Included were fifty two elderly women (age $72.6 \pm 65.9$ years, mean $\pm \mathrm{SD}$ ) with knee osteoarthritis undergoing primary knee arthroplasty. Health-related quality of life, physical activity, pain and function and the number of steps were assessed before, 3 and 6 months post-operatively. We used the Medical Outcomes Study Short Form (SF-36), the Physical Activity Scale for the Elderly (PASE) and the pedometer SW200 Digiwalker of Yamax.

Results: Patients showed a significant improvement $(p<0.01, \eta 2=0.22)$ in health-related quality of life, particularly in physical function, $(p<0.001)$ body pain $(p<0.001)$ and vitality scale $(p<0.001)$ of SF-36 at 3 and 6 months after the procedure. Physical activity (PASE score) increased at 3 and 6 months after arthroplasty $(p<0.001, \eta 2=0.74)$, and the number of steps increased 6 months after, compared to the assessment that took place 3 months after operation $(p<0.001)$.

Conclusions: Our results suggest that total knee arthroplasty leads to a gradual improvement in quality of life of elderly patients over the first 6 post-operative months.
\end{abstract}

Keywords: Knee osteoarthritis, older adults, pedometers, PASE, SF-36, total knee arthroplasty.

\section{INTRODUCTION}

Knee osteoarthritis is the most common disease of joints in older adults around the world. The prevalence of knee osteoarthritis is higher among subjects aged 70-74 years. Nowadays, the percentage of people aged over 60 in Europe amounts to $22 \%$ and it is going to be $27 \%$ until 2020 . According to Eurostat, in Greece the increase in the percentage of the subjects aged 65-79 years is the highest among all members of the E.U. [1]. The number of patients has increased over the last years [2]. This epidemiological data lead to the conclusion that knee osteoarthritis tends to become a major health problem, possibly affecting daily life.

The term osteoarthritis (OA), according to American College of Rheumatology, is a combination of conditions characterized by disorder of the cartilage and degeneration of the joint, and leads to disability $[3,4]$. The main symptom is pain [4], which initially occurs in everyday activity, but later aggravates and tends to get worst at night. Conservative treatment requires a combination of non-pharmacological and pharmacological modalities. Surgery is indicated when

*Address correspondence to this author at the Department of Anatomy, Medical School of Alexandroupolis, Democritus University of Thrace, 68100, Alexandroupolis, Greece; Tel: 00306972707384; Fax:00302106096722; E-mail: stkapetanakis@yahoo.gr the patient's symptoms can no longer be medically relieved, while physical and radiological findings deteriorate.

Total knee arthroplasty is a common, reliable surgical operation performed at the late stages of osteoarthritis. It allows patients to regain their activity [3], reduces pain and improves their quality of life [4-10]. It is one of the most common orthopedic operations. Most patients report a satisfactory improvement after 3-6 months of the operation and a further slight improvement during the next 2 years. Excellent benefits are observed mostly after 6 months, 12 [6, $11,12]$ or 24 months $[8,13,14]$. A metanalysis of 130 studies indicated that these favorable results continue over time [5].

The aim of this study was to evaluate the changes in quality life of patients after total knee arthroplasty and to assess the changes in physical activity by using a self reported questionnaire and by counting the number of steps at 3-6 months post-operatively.

\section{PATIENTS AND METHODS}

This study was performed by the Orthopedic Department of Amalia Fleming General Hospital in Athens in cooperation with Orthopedic Department at University Hospital of Alexandroupolis. Fifty-two patients participated, all Caucasian women between $65-83$ years with knee OA 
Table 1. Demographic and Anthropometric Characteristics of the Women Participating to the Research

\begin{tabular}{|c|c|}
\hline Characteristics & M \pm T.A \\
\hline \hline Age & $72.6 \pm 5.9$ \\
\hline Weight & $74.2 \pm 15$ \\
\hline Height & $29.79 \pm 5.27$ \\
\hline BMI & $68 \%$ Married, $22 \%$ Widowed, $10 \%$ Divorced \\
\hline Family status & $74 \%$ Primary School, $14 \%$ High School, $12 \%$ coll.-university \\
\hline Education & $48 \%$ none, $52 \%$ with SD $(76 \%$ one vessel, $24 \% \geq 2)$ \\
\hline Systematic disease & $24 \%$ yes \\
\hline Arthroplasty of the other leg & $23 \%$ at other joint, $9 \%$ at the particular \\
\hline Pain (until 6 months after surgery) &
\end{tabular}

that have been under surgery between January 2006 and June of 2009. All patients suffered from osteoarthritis while we excluded patients with a) revision b) post surgical infection c) neuromuscular disorders and d) those who did not want to be a part of this study. Anthropometric and demographic characteristics of these patients are shown at the following table (Table 1).

\section{Procedure}

Questionnaires SF-36 and PASE were completed by the patients a week before surgery. A personal interview was chosen to complete the questionnaires because a lot of patients were analphabet. In the first interview we wrote down the medical history, some data of their life, we answered the question referring to their quality of life and physical ability and we measured their physical characteristics. The same procedure has been repeated three and six months after the operation either at their house or in the hospital. At that time we gave instructions about how to use the pedometer, the right way to put it on and taking it off at night, which was used only for one week. After this week the researcher wrote down the number of the steps for each patient. Six months after the operation we did this procedure once more. In both measures, the recording lasted seven days.

\section{Measuring Instruments \\ Evaluating Quality of Life}

Questionnaire SF-36, that has been translated to 40 different languages throughout the world [15], is an instrument evaluating physical and mental health of the elderly $[14,15]$. It is reliable, has been used by researches in other countries [15, 16] and is considered as a medical instrument [17]. Healthrelated quality of life has a broad sense, combining physical, mental and social affections of the illness and it is very subjective according to someone's life. SF-36 questionnaire is separated to 2 basic levels, the physical component and the mental component. It includes 36 questions in total, that estimate 8 units; 10 questions for physical function, 2 questions for social behavior, 4 questions for the physical role, 2 questions for the bodily pain, 5 for mental health, 3 for the emotional role, 4 vitality and 6 questions for general health [18]. The score ranges from 0 to 100 , best quality of life corresponding to 100 and worst to 0 .

\section{Assessment of Physical Activity}

In order to record physical activity, we used the questionnaire of physical activity for the elderly "PASEphysical activity scale for the elderly", which includes questions referring to physical activity of the last 7 days [19]. PASE consists of three units. The first unit includes questions for the frequency of some activities in the patient's spare time as they have to tell us how often they participate to sedentary activity (e.g. TV), everyday activity (walking), light sports (fishing, golf), sports with great intense (dancing) and exercise for the increase of the muscular system (e.g. weights). The second unit includes questions referring to inner house activity. The third unit includes questions referring to the duration and the type of the patient's job for the last week. The total score for each patient is measured by adding all the subscores. The validity and reliability of this instrument in the English population is referred at 0.65 and 0.75 respectively, while the reliability in the Greek population is high.

\section{Recording the Number of the Steps}

The number of steps was recorded by Digiwalker Yamax pedometer. The patients wore the pedometer on the belt recording the vertical accelerations of the hip during walking. Pedometers can record the most of the activities an old person does such as walking or running but they cannot record all of them (e.g. swimming, using a bicycle). Their application and results are fully understandable while walking is the most common physical activity in the elderly, especially after total knee arthroplasty. These pedometers are very accurate when the patient goes only for a medium intense walking [20]. The pedometers have many applications: 1) personal differentiation according to the number of steps, 2) measuring the increase of the physical activity after the operation, 3) comparing different populations and 4) comparing the temporal tension [9].

\section{Statistical Analysis}

ANOVA repeated measures was used to examine the difference between the three measures (before and 3 and 6 months after the operation). We set as repeated factor the measure in 3 levels (before the operation, 3 and six months later), while dependent variables were the score for the quality of life (SF-36) and the total score for the physical 
activity (PASE). Differences between mean values of the repeated factor of the subunits were analyzed by the Sidak multiple comparison control. Number of the steps of the two different periods were compared by t-test. The level of importance was set at $\mathrm{p}<0.05$.

\section{RESULTS}

\section{Quality of Life; SF-36 Questionnaire}

Total score for SF-36 questionnaire; The total score between the women that participated in the research was significantly higher after the operation $\left(\mathrm{F}_{2,50}=69.366, \mathrm{p}<.01\right.$, $\mathrm{n}^{2}=.72$ ). According to the multiple comparison Sidak test we detected significant differences between the results before the operation and 6 months after $(p<.05)$, while there was also significant difference between the results at three and six months after the operation ( $\mathrm{p}<.05$, Table 2 ).

According to the results of the ANOVA analysis with repeated measures there has been a significant effect of the factor "measure" to the level of physical component $\left(\mathrm{F}_{2}, 50=73.65\right.$ $\left.\mathrm{p}<0.001, \mathrm{n}^{2}=0.74\right)$. Moreover the sidak tests showed significant differences to the results before the operation and $3(p<0.001)$ and 6 months $(p<0.001)$ after. In parallel there was a significant difference to the measures between 3 and 6 months after the operation ( $\mathrm{p}<0.01$, Table 2 ). As far as all 4 units of the level are concerned we wrote down a significant affection of the factor "measure"; physical function $\left(\mathrm{F}_{2,50}=74.10 \mathrm{p}<0.001, \mathrm{n}^{2}=0.74\right)$, physical role $\left(\mathrm{F}_{2},{ }_{50}=9.13 \mathrm{p}<0.001, \mathrm{n}^{2}=0.20\right)$, body pain $\left(\mathrm{F}_{2}\right.$, $\left.{ }_{50}=149.65, \mathrm{p}<0.001, \mathrm{n}^{2}=0.90\right)$ and general health $\left(\mathrm{F}_{2,50}=79.09\right.$, $\mathrm{p}<0.001, \mathrm{n}^{2}=0.75$ ). Table 2 shows the most important differences that came up by using the multiple comparison Sidak test.

According to the results of the ANOVA analysis with repeated measures there has been a significant affection of the factor "measure" to the level of mental component health $\left(\mathrm{F}_{2}\right.$, ${ }_{50}=42.80 \mathrm{p}<0.001, \mathrm{n}^{2}=0.75$ ). Moreover the Sidak tests showed significant differences to the results before the operation and 3 $(p<0.001)$ and 6 months $(p<0.001)$ after, while there was no important difference between the measures in 3 and 6 months ( $>0.05$, Table 2). As far as all 4 units of this level are concerned we wrote down a significant affection of the factor "measure"; vitality $\left(\mathrm{F}_{2,50}=49.00, \mathrm{p}<0.001, \mathrm{n}^{2}=0.65\right)$, social behavior $\left(\mathrm{F}_{2,50}=30.01, \mathrm{p}<0.001, \mathrm{n}^{2}=0.49\right)$, emotional role $\left(\mathrm{F}_{2}\right.$, $\left.{ }_{50}=18.85, \mathrm{p}<0.001, \mathrm{n}^{2}=0.35\right)$ and mental health $\left(\mathrm{F}_{2}, 50=32.65\right.$, $\left.\mathrm{p}<0.001, \mathrm{n}^{2}=0.53\right)$. Table 2 shows the most important differences at multiple comparisons by Sidak test.

The averaged stay of the patients inside the hospital was 14 days. Complications like soft tissue infections, fever, deep venous thrombosis, pulmonary embolism, pneumonia, heart attack, stroke were managed inside the hospital and they didn $\mathrm{t}$ influence physical ability three and six months after the day of the surgery (Table $\mathbf{3}$ ).

\section{Physical Activity; PASE Questionnaire}

According to the results of the ANOVA analysis with repeated measures there has been a significant affection of the factor "measure" to the total women's activity $\left(F_{1,25}=18.47\right.$ $\mathrm{p}<0.001, \mathrm{n}^{2}=0.45$ ). Moreover the Sidak tests showed significant differences to the results before the operation and 6 months $(p<0.001)$ after, while there was no significant difference between the measures in 3 and 6 months ( $p>0.05$, Fig. 1).

\section{Number of Steps}

The number of steps per day was $2693 \pm 1368$ at 3 months and $3518 \pm 1835$ at 6 months after the operation. The number of steps was significantly higher at 6 months after the operation as compared to 3 months $\left(\mathrm{t}_{25}=-6.51, \mathrm{p}<0.001\right.$, Fig. 2$)$.

\section{DISCUSSION}

In the preoperative measure, the results in the SF-36 questionnaire were low (29.33 units, indicating low quality of life. Similar results were reported in other studies, with preoperative measure ranging between 27.6 and 28.8 units [4, 7]. The total score seems to have doubled in the SF-36 questionnaire after six months, and this is a strong indication that total knee arthroplasty increased the quality of life. In a previous Greek study of 193 old subjects without serious health problems, results were higher $(\mathrm{SF}-36=74.07)$, while in our study we measured SF-36=62.35. A potential cause of this difference is the fact that our patients had many health problems, both organic and psychological, that often lead to

Table 2. Values of SF-36 Total Score and Score for Every Unit of Physical and Mental Level Before, at 3 and 6 Months After the Operation

\begin{tabular}{|c|c|c|c|c|c|c|c|}
\hline Level of Physical Component Score & Before & 3 Months & 6 Months & \multicolumn{4}{|c|}{ Norms for Women $>65$ Yrs } \\
\hline TotalSF-36 score & $29.33 \pm 11.3$ & $55.14 \pm 2.4^{*}$ & $62.35 \pm 2.7 * \#$ & & & & \\
\hline Physical function & $29.35 \pm 12.40$ & $64.12 \pm 19.31^{*}$ & $73.32 \pm 22.80 * \#$ & 40 & 66.7 & 85 & 61.86 \\
\hline Physical role & $0.98 \pm 3.80$ & $18.95 \pm 29.73^{* *}$ & $28.84 \pm 31.49^{*}$ & 0 & 75 & 100 & 56.11 \\
\hline Bodily pain & $18.43 \pm 9.57$ & $65.12 \pm 12.47 *$ & $72.11 \pm 15.09 * \#$ & 41 & 62 & 84 & 63.44 \\
\hline Level of physical component score & $23.72 \pm 1.9$ & $49.58 \pm 2.6^{*}$ & $56.70 \pm 2.9^{*} \#$ & 32 & 42.93 & 49.83 & 41.02 \\
\hline Vitality & $38.23 \pm 12.43$ & $63.34 \pm 10.25^{*}$ & $67.46 \pm 8.04 * \#$ & 40 & 55 & 75 & 55.46 \\
\hline Social function & $45.69 \pm 24.84$ & $67.76 \pm 25.78^{*}$ & $76.42 \pm 20.76^{*}$ & 62.5 & 87.5 & 100 & 77 \\
\hline Emotional role & $12.94 \pm 19.42$ & $45.24 \pm 48.60 * *$ & $65.05 \pm 43.96^{*}$ & 33.3 & 100 & 100 & 73.38 \\
\hline Mental health & $42.95 \pm 15.34$ & $66.11 \pm 12.29 *$ & $63.13 \pm 9.14^{*}$ & 64 & 80 & 88 & 74.71 \\
\hline
\end{tabular}

${ }^{*} \mathrm{p}<0.001$ compared to the first assessment, ${ }^{* *} \mathrm{p}<0.05$ compared to the first assessment,

$\neq \mathrm{p}<0.01$ compared to the assessment after three months. 
disability [18-20]. Many other studies also confirm the particular characteristics of the patients with osteoarthritis comparing to these who do not have any systematic disease [10, $21,22]$. Results similar to the general population were found in some studies [12], but only in very old subjects ( $\geq 75$ years). Despite showing improvement between pre- and postoperative measures, all other categories differed significantly from the general population in all measures.

Table 3. Complication Following Total Knee Arthroplasty

\begin{tabular}{|c|c|}
\hline Complications & Number of Patients \\
\hline \hline Brochopneumonia & $4(7,69 \%)$ \\
\hline Wound Haematoma & $7(13,46 \%)$ \\
\hline Soft tissue infection & $6(11,54 \%)$ \\
\hline Deep venus thrombosis & $8(15,38 \%)$ \\
\hline Palmonary embolism & $1(1,9 \%)$ \\
\hline Strock & $0(0 \%)$ \\
\hline Heart attach & $5(9,61 \%)$ \\
\hline
\end{tabular}

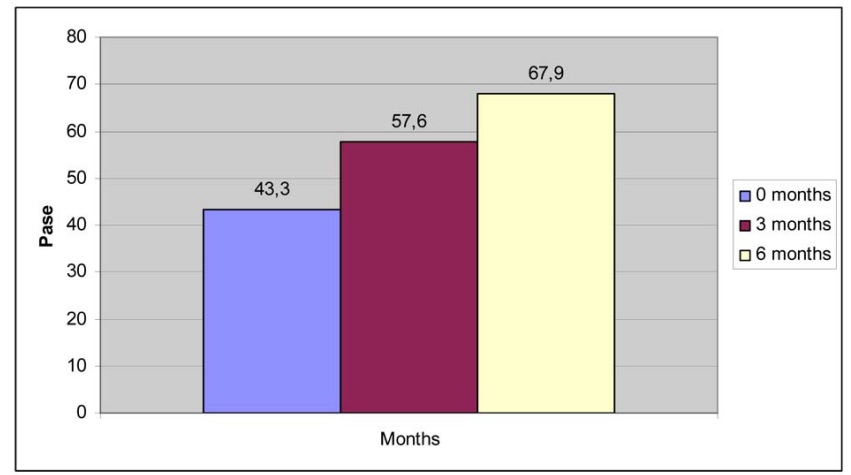

Fig. (1). Results of PASE Questionnaire before, at 3 and 6 months ${ }^{*}$ (significant difference, $\mathrm{p}<0.001$ ) after the operation.

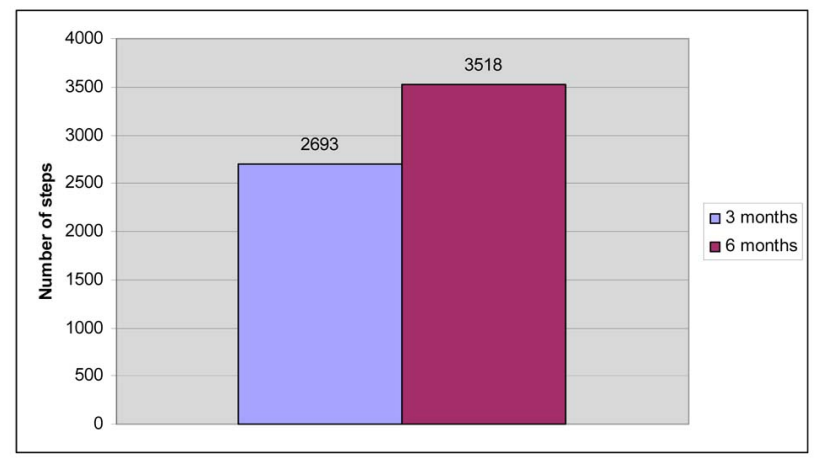

Fig. (2). Number of steps per day at 3 and 6 months $^{*}$ (significant difference, $\mathrm{p}<0.001$ ) after the operation.

In our study, the level of physical components started with poor results preoperatively, which improved after 3 months and continued to increase 6 months later. Our findings were similar to those of Marx et al. [4] and Hartley et al. [11], who found improvement in the physical component. In parameters of pain, physical function physical role and emotional role we observed the same findings with other studies [12]. Compared to other studies, the lowest value of pain is reported in our study $[6,23]$. A possible cause seems to be the attitude of Greek patients who hesitate to visit the orthopedic surgeon at the early stages of osteoarthritis and also hesitate to go to surgery. All patients referred preoperative severe pain and $85 \%$ of them mentioned that it was unendurable.

Postoperatively, we observed improvement of pain, physical function, and social behavior, in agreement with other studies [6, 24-27]. These results confirm the important role of total knee arthroplasty in reducing pain and therefore the improvement of the quality of life $[28,29]$. It is very significant that the improvement was observed only three months after the operation. All patients reported reduction of pain which in six months reached the normal values of the general population [30]. Almost the same values have been observed in other studies [6] one year after the operation. That means that the best result is accomplished six months after the operation with small further differentiations.

In the unit of general health, even though there has been improvement, we did not reach the normal values, and the further improvement was also very modest. Similar results were found in other studies [12,31]. The reason may lie in their past medical history and other diseases that continue to play important role in the patient's general health even after the arthroplasty.

Mental health was the only unit exhibiting an insignificant decrease between 3 and 6 months, despite the significant improvement following operation. This finding differs from these of previous studies $[10,22,32]$, where there was no decrease at post-operative assessments.

Many studies have shown that regular physical activity is a very useful way to maintain a good physical level in the elderly. Unfortunately this cannot be written down in this study. No woman in Greece referred any kind of regular physical activity compared to the other European countries. The pain and stiffness of the joint preoperatively were so intense that $36 \%$ of the patients were limited only to indoor physical activity. On the contrary, 3 months after the arthroplasty $96 \%$ of these women walked outside the house and increased the frequency and the duration of their daily activities. Even though physical activity has increased significantly 3 and 6 months after the operation, there was no difference between these two periods.

Steps per day showed a satisfactory physical activity in 3 months which was increased more 6 months after the operation. Even though there are few studies [33-35] that record the daily number of steps of patients after total knee arthroplasty and even fewer referring to women over 65 years, the number of steps in our study seems to be in agreement with Schmalzried et al. [33]. Among 111 patients, the mean number of steps was 3514 [33], which is relatively the same to our results. The greatest difference is with Zahiri et al. [35], where women after total knee and hip arthroplasty walked approximately 4363 steps/day. The largest number of steps (5737) was recorded in the study of Silva et al, but this work included younger patients (both men and women) after knee and hip arthroplasty [34]. It is known that younger patients are more active than older ones, men are more active than women, and also patients after hip replacement are more active than those after knee replacement [10]. Accordingly, results are not directly comparable.

\section{CONCLUSIONS}

This is the first study in Greece which records the physical ability(by counting the steps) and the quality of life in Greek 
Elderly Women following total knee artroplasty. Patients exhibited multiple improvements after total knee arthroplasty, which included many parameters relating to quality of life. The parameters showing the most significant improvement were pain, physical function and vitality. The improvement was significant in both post-operative measures, but also between 3 and 6 months after the operation, while it finally reached the normal values of age-matched healthy population. The remaining parameters also showed a significant improvement but to a lower extent. Social behavior improved significantly in both post-operative measures and reached the normal values in six months, while the units of psychological health, general health, physical and emotional role improved but did not reach the normal values, even 6 months later. Overall, our results suggest that total knee arthroplasty improves the quality of life and physical activity of patients with OA knee over a short period of time.

\section{CONFLICTS OF INTEREST /ACKNOWLEDGEMENT}

The authors declare that they have no any conflict of interest. We also declare that we do not have any financial relationship with any organization and nobody has sponsored this research.

\section{REFERENCES}

[1] National Statistical Service of Greece (2004). Statistical Greek Bureau 2003.

[2] Martin JA, Buckwalter JA. Aging and the pathogenesis of osteoarthritis- implications for cartilage repair. Eur Cells Mater 2002; 4(Suppl 1): 1473-2262.

[3] Ethgen O, Bruyere O, Richy F, et al. Health related quality of life in total hip and total knee arthroplasty. A qualitative and systematic review of the literature. J Bone Joint Surg 2004; 86-A (5): 963-74.

[4] Marx Rg, Jones EC, Atwan NC, et al. Measuring improvement following total hip and knee arthroplasty using patient-based measures of outcome. J Bone Joint Surg Am 2005; 87(9): 1999-2005.

[5] Callahan CM, Drake BG, Heck DA. Patient outcomes following tricompartmental total knee replacement. A meta-analysis. JAMA 1994; 271: 1349-57.

[6] Fitzerald JD, Orav EJ, Lee TH, et al. Patient quality of life during the 12 months following joint replacement surgery. Arthritis Rheumatol 2004; 51(1): 100-109.

[7] Kane LR, Khaled JS, Wilt JT, et al. The functional outcomes of total knee arthroplasty. J Bone Joint Surg 2005; 87A (8): 1719-24.

[8] Kiebzak GM, Campell M, Mauerhan DR. The SF-36 general health status survey documents the burden of osteoarthritis and the benefits of total joint arthroplasty: But why should we use it? Am J Manag Care 2002; 8: 463-74.

[9] Schneider PL, Crouter SE, Basset DR. Pedometer measures of freeliving physical activity: comparison of 13 models. Med Sci Sports Exerc 2004; 36(2): 331-5

[10] Jones CA, Voaklander DC, Johnston DW, et al. Health related quality of life outcomes after total hip and knee arthroplasties in a community based population. J Rheumatol 2000; 27(7): 1745-52.

[11] Hartley CR, Barton-Hanson GN, Finley R, et al. Early patient outcomes after primary and revision total knee arthroplasty. J Bone Joint Surg Br 2002; 84B: 994-9.

[12] March LM, Cross MJ, Lapsley H, et al. Outcomes after hip or knee replacement surgery for osteoarthritis. A prospective cohort study comparing patients' quality of life before and after surgery with agerelated population norms. Med J Aust 1999; 171(5): 235-8.
[13] McGuigan FX, Hozack WJ, Moriarty L, et al. Predicting quality-of-life outcomes following total joint arthroplasty. Limitations of the SF-36 Health Status Questionnaire. J Arthroplasty 1995; 10(6): 742-7.

[14] Ware JE Jr, Sherbourne CD. The MOS 36-item short-form healthy survey (SF-36). Conceptual framework and item selection. Med Care 1992; 30(6): 473-83.

[15] Ren XS, Chang K. Evaluating health status of elderly Chinese in Boston. J Clin Epidemiol 1998; 51(5): 429-35.

[16] Fukuhara S, Ware JE, Kosinski M, et al. Psychometric and clinical tests of validity of the Japanese SF-36 Health Survey. J Clin Epidemiol 1998; 51(11): 1045-53.

[17] Pukrop R, Schlaak V, Moller-Leimkuhler AM, et al. Reliability and validity of quality of life assessed by the short-form 36 and the modular system for quality of life in patients with schizophrenia and patients with depression. Psychiatry Res 2003; 119(12); 63-79.

[18] Peat G, McCarney R, Croft P. Knee pain and osteoarthritis in older adults: a review of community burden and current use of primary health care. Ann Rheum Dis 2001; 60(2): 91-7.

[19] Washburn RA, Ficker Jl. Physical Activity Scale for the Elderly (PASE): the relationship with activity measured by a portable accelerometer. J Sports Med Phys Fitness 1999; 39(4): 336-40.

[20] Crouter SE, Schneider PL, Karabulut M, et al. Validity of 10 electronic pedometers for measuring steps, distance and energy cost. Medicine and Science sports and Exercise 2003; 35: 1455-60.

[21] Dominick KL, Ahern FM, Gold CH, et al. Health-related quality of life and health service use among older adults with osteoarthritis. Arthritis Rheumatol 2004; 51: 326-31.

[22] Jones CA, Voaklander Dc, Suarez-Alma ME. Determinants of function after total knee arthroplasty. Phys Ther 2003; 83(8): 696-706.

[23] Jones CA, Voaklander DC, Johnston DW, et al. The effect of age on pain, function and quality of life after total hip and knee arthroplasty. Arch Intern Med 2001; 161(3): 454-60.

[24] Hawker G, Wright J, Coyte P, et al. Health related quality of life after knee replacement. J Bone Joint Surg 1998; 80(2): 163-173.

[25] Salmon P, Hall GM, Peerbhoy D et al. Recovery from hip and knee arthroplasty: Patients' perspective on pain, function, quality of life and well-being u to 6 months postoperatively. Arch Phys Med Rehabil 2001; 82(3): 360-6.

[26] Shields RK, Enloe LJ, Leo KC. Health related quality of ; ife in patients with total hip or knee replacement. Arch Phys Med Rehabil 1999; 80(5): 572-9.

[27] Van Essen GJ, Chipchase LS, O'Connor D et al. Primary total knee replacement: shorterm outcomes in an Australian population. J Qual Clin Pract 1998; 18(2): 135-42.

[28] Kauppila AM, Kyllonen E, Ohtonen P, et al. Multidisciplinary rehabilitation after primary total knee arthroplasty: a randomized controlled study of its effects on functional capacity and quality of life.. Clin Rehabil 2010; 24 (5): 398-411

[29] Nunez M, Lozano L, Nunez E. et al. Total knee replacement and health - related quality of life: factors influencing long - term outcomes. Arthritis Rheumetol 2009; 61 (8): 1062-9

[30] Washburn RA, Smith KW, Jette AM, et al. The Physical Activity Scale for the Elderly (PASE): development and evaluation. J Clin Epidemiol 1993; 46(2): 153-62

[31] Ritter MA, Albohm MJ, Keating EM, et al. Comparative outcomes of total joint arthroplasty. J Arthroplasty 1995; 10(6): 737-41.

[32] Dawson J, Fitzpatrick R, Murray D, et al. Questionnaire on the perception of patients about total knee replacement. J Bone Joint Surg (Br) 1998; 80-B: 63-9.

[33] Schmalzried TP, Szuszczewicz ES, Northfield MR, et al. Quantitative assessment of walking activity after total hip or knee replacement. J Bone Joint Surg Am 1998; 80(1): 54-9.

[34] Silva M, McClung CD, Dela Rosa MA, et al. Activity sampling in the assessment of patients with total joint arthroplasty. J Arthroplasty 2005; 20(4): 487-91.

[35] Zahiri CA, Schmalzried TP, Szuszczewicz ES, et al. Assessing activity in joint replacement patients. J Arthroplasty 1998; 13(8): 890-5. 